\section{PERANAN POHON TERHADAP TINGKAT KENYAMANAN LINGKUNGAN KAMPUS UNIVERSITAS LANCANG KUNING PEKANBARU}

\author{
(The Role of Tree on the Level of Comfortable Environment Campus Universitas Lancang \\ Kuning Pekanbaru)
}

\author{
Hadinoto, Eni Suhesti, Eno Suwarno
}

Staf Pengajar Fakultas Kehutanan Universitas Lancang Kuning

Jln. Yos Sudarso Km. 8 Rumbai Pekanbaru Riau Telp./Fax. (0761) 54092

Email:hadinoto@unilak.ac.id; suhestieni@unilak.ac..id; enosuwarno@unilak.ac.id

Diterima: 01 Oktober 2020, Direvisi: 05 Oktober 2020, Disetujui: 22 Oktober 2020

DOI: 10.31849/forestra.v15i2.5050

\begin{abstract}
Regional development has a tendency to minimize green open space and also remove the face of nature. The increasingly disharmonious relationship between humans and nature has resulted in ecological deterioration in the environment. Less land covered by trees causes the environment to become hot. The Lancang Kuning University Campus is one of the places of education in which the entire academic community, employees and other parties are located. In carrying out all campus activities, a comfortable environment is needed. The objectives are: to identify tree characteristics in the faculty environment; measuring the comfort level of the faculty environment. The objects this research are tree types. The equipment used is: thermohigro, camera, phi band, haga meter, roll meter, stationery. While the material used is thally sheet. Primary data taken in the field are tree data, temperature and humidity. The comfort index is categorized: comfortable, if it has a value of $21 \leq T H I$ $\leq 24$; quite comfortable $24<T H I \leq 26$ and not comfortable THI> 26. There were 31 tree species with 472 trunks with an average diameter of 19 centimeters and an average height of 10 meters. The Temperature Humidity Index (THI) of all faculties is in the "uncomfortable" category.
\end{abstract}

Key words: humidity temperature; Temperature Humidity Index; tree;

\begin{abstract}
ABSTRAK
Pembangunan wilayah memiliki kecenderungan untuk meminimalkan ruang terbuka hijau dan juga menghilangkan wajah alam. Semakin tidak harmonisnya hubungan manusia dengan alam mengakibatkan keadaan lingkungan mengalami kemunduran secara ekologi. Berkurangnya lahan yang ditutupi oleh pepohonan mengakibatkan lingkungan menjadi panas. Kampus Universitas Lancang Kuning merupakan salah satu tempat pendidikan yang di dalamnya terdapat segenap civitas akademika, karyawan dan pihak lainnya. Dalam melakukan segala kegiatan kampus diperlukan lingkungan yang nyaman. Tujuan penelitian ini adalah : (1) Mengidentifikasi karakteristik pohon di lingkungan fakultas (meliputi jenis dan jumlah); (2) Mengukur tingkat kenyamanan lingkungan fakultas. Objek pada penelitian ini adalah jenis-jenis pohon. Peralatan yang digunakan adalah: thermohigro, kamera, phi band, haga meter, meteran gulung, alat tulis. Sedangkan bahan yang
\end{abstract}




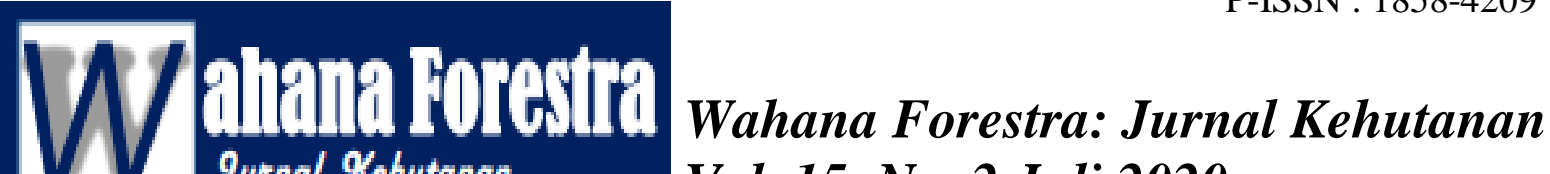 gutenal Kehutanan}

digunakan thally sheet. Data primer yang diambil di lapangan adalah data pohon (jumlah dan jenis, diamater, tinggi total dan tinggi bebas cabang), suhu dan kelembaban. Indeks kenyamanan dikategorikan : nyaman, jika memiliki nilai $21 \leq \mathrm{THI} \leq 24$; cukup nyaman, nilai $24<\mathrm{THI} \leq 26$ dan tidak nyaman, nilai THI > 26. Ditemukan sebanyak 31 jenis pohon dengan 472 batang dengan ratarata diameter 19 centimeter dan rata-rata tinggi 10 meter. Temperature Humidity Index (THI) dari seluruh fakultas dalam kategori " tidak nyaman".

Kata kunci : kelembaban; pohon; suhu; Temperature Humidity Index

\section{PENDAHULUAN}

Pembangunan wilayah sering dicerminkan oleh adanya perkembangan fisik yang lebih banyak ditentukan oleh sarana dan prasarana yang ada. Gejala pembangunan wilayah pada masa lalu memiliki kecenderungan untuk meminimalkan ruang terbuka hijau dan juga menghilangkan wajah alam. Lahan-lahan banyak dialih-fungsikan menjadi pusatpusat perbelanjaan, pemukiman, tempat rekreasi, industri dan lain-lain termasuk tempat-tempat pendidikan.

Semakin tidak harmonisnya hubungan manusia dengan alam mengakibatkan keadaan lingkungan maju secara ekonomi tetapi mengalami kemunduran secara ekologi. Padahal kestabilan ekologi sangat penting, sama pentingnya dengan kestabilan ekonomi. Menurut Dahlan (2013) bahwa terganggunya kestabilan ekologi suatu wilayah, maka timbul beberapa permasalahan alam antara lain : suhu udara perkotaan meningkat, penurunan air tanah, banjir/genangan, penurunan permukaan tanah, intrusi air laut, abrasi pantai, pencemaran air, pencemaran udara seperti meningkatnya kadar $\mathrm{CO}$, rusaknya ozon, banyak debu, suasana yang gersang, monoton, bising dan kotor.

Ruang Terbuka Hijau (RTH) mempunyai manfaat terhadap komponen lingkungan diantaranya menyerap panas, mengurangi tingkat kebisingan dan pencemaran udara. RTH melalui perannya sebagai pengatur iklim mikro dapat menurunkan suhu permukaan yang secara langsung berpengaruh terhadap sebaran suhu udara dan dapat meningkatkan kenyamanan hidup masyarakat (Ahmad dkk, 2012). Pertambahan jumlah penduduk yang tidak diiringi oleh peningkatan daya dukung lingkungan dapat mengakibatkan timbulnya masalah perkotaan seperti meningkatnya suhu udara dan penurunan kualitas lingkungan. Permasalahan kerusakan lingkungan hidup dapat diatasi dengan keberadaan RTH.

Pada wilayah perkotaan juga dapat dijumpai lokasi-lokasi yang memiliki suhu permukaan daratan yang lebih rendah dibandingkan dengan wilayah sekitarnya dimana lokasi tersebut memiliki tutupan vegetasi yang rapat (Rahmah, 2017). Perbedaan suhu pada ruang hijau perkotaan berkisar antara $1-2^{\circ} \mathrm{C}$ bahkan mencapai 5$7^{\circ} \mathrm{C}$ lebih dingin dibandingkan wilayah perkotaan lainnya (Xin, et all, 2010). Menurut Bunyamin (2010), unsur-unsur iklim mikro yang mempengaruhi keadaan ruang terbuka hijau meliputi suhu udara, kelembapan udara dan intensitas cahaya. Penelitian Gucci et all (2016) menunjukkan bahwa unsur yang mempengaruhi iklim mikro di suatu ruang terbuka hijau adalah intensitas cahaya, kerapatan tajuk, suhu dan kelembapan udara, serta kecepatan angin.

Berkurangnya lahan yang ditutupi oleh pepohonan mengakibatkan lingkungan 
menjadi panas. Kampus Universitas Lancang Kuning merupakan salah satu tempat pendidikan yang di dalamnya terdapat segenap civitas akademika, karyawan dan pihak lainnya. Dalam melakukan segala kegiatan kampus diperlukan lingkungan yang nyaman. Secara umum suhu udara pada daerah berpepohonan lebih nyaman, bila dibandingkan dengan lahan yang tidak ditumbuhi pohon. Pada lingkungan fakultas Universitas Lancang Kuning secara umum belum banyak ditanami pohon. Berdasar pada hal tersebut perlu dilakukan kajian tentang karakteristik pohon dan tingkat kenyamanan di lingkungan fakultas yang ada di kampus Universitas Lancang Kuning.

\section{Tujuan Penelitian}

Tujuan penelitian ini adalah : mengidentifikasi karakteristik pohon di lingkungan fakultas (meliputi jenis, jumlah, luas tutupan tajuk) dan mengukur tingkat kenyamanan lingkungan fakultas.

\section{Manfaat Penelitian}

Penelitian ini diharapkan dapat memberikan manfaat sebagai sumber informasi pendukung kegiatan di lingkungan kampus dan bahan pertimbangan untuk pengembangan pembangunan kampus dengan tetap memperhatikan fungsi ekologi dan lingkungan.

\section{METODE PENELITIAN Tempat dan Waktu}

Penelitian ini dilaksanakan di lingkungan fakultas kampus Universitas Lancang Kuning Pekanbaru. Waktu penelitian mulai November 2019 - Juni 2020 .

\section{Alat dan Bahan}

Objek yang diteliti pada penelitian ini adalah jenis-jenis pohon. Peralatan yang digunakan adalah: thermohigro, kamera, phi band, haga meter, meteran gulung, alat tulis. Sedangkan bahan yang digunakan thally sheet sebagai bahan mencatat data

\section{Jenis Data}

Data Primer

Data primer yang diambil di lapangan adalah data pohon (jumlah dan jenis, diamater, tinggi total dan tinggi bebas cabang), suhu dan kelembaban.

\section{Data Sekunder}

Data sekunder dikumpulkan melalui studi literatur. Data sekunder merupakan data pendukung yang sangat penting dan dikumpulkan dari berbagai sumber antara lain buku teks, hasil-hasil penelitian, jumal penelitian, internet dan sumber lainnya.

\section{Metode Pengumpulan Data}

Pengumpulan data karakteristik pohon dilakukan dengan cara sensus pada setiap fakultas untuk tingkat pohon dan tiang. Data yang diukur antara lain jenis dan jumlah, diameter, tinggi bebas cabang, tinggi total.

Pengumpulan data untuk tingkat kenyamanan dilakukan melalui pengukuran suhu dan kelembaban. Pengkuran dilakukan pada setiap fakultas dengan ulangan sebanyak 3 (tiga) kali. Pengukuran dilakukan pada pagi hari pukul $07.00-$ $08.00 \mathrm{WIB}$; siang hari pukul $12.00-13.00$ WIB dan sore hari pukul $17.00-18.00$ WIB. Thermohigro ditempatkan pada batang yang dipilih yang dianggap mewakili kondisi fakultas dengan ketinggian 1,5 meter. 


\section{Analisis Data}

Analisis data dilakukan untuk memperoleh kondisi iklim mikro yaitu tingkat kenyaman pada lokasi penelitian. Data suhu dan kelembaban udara dianalisis dengan rumus (Handoko, dkk, 1994):

$$
\begin{aligned}
& \mathbf{T}=\frac{[(2 \text { Tpagi })+(\text { Tsiang })+(\text { Tsore })]}{4} \\
& \text { RH }=\frac{[(2 \text { RHpagi })+(\text { RHsiang })+(\text { RHsore })]}{4}
\end{aligned}
$$

Keterangan :

$\mathrm{T}=$ rata-rata suhu udara harian $\left({ }^{\circ} \mathrm{C}\right)$

$\mathrm{RH}=$ rata-rata kelembapan udara harian $(\%)$

Indeks kenyamanan digunakan untuk mengetahui tingkat kenyamanan pada setiap fakultas menggunakan rumus Temperature Humidity Index (THI) yang disadur dari (Emmanuel, 2005):

$$
\begin{gathered}
\text { THI }=\mathbf{0 , 8} \mathbf{T}+\frac{(\boldsymbol{R H} \boldsymbol{x})}{\mathbf{5 0 0}} \\
\text { Keterangan: } \\
\text { THI }=\text { Temperature Humidity Index } \\
\mathrm{T} \quad=\text { suhu udara }\left({ }^{\circ} \mathrm{C}\right) \\
\mathrm{RH}=\text { kelembapan udara }(\%)
\end{gathered}
$$

Indeks kenyamanan termal digolongkan berdasarkan kategori nyaman, cukup nyaman, dan tidak nyaman sebagai berikut (Nieuwolt, 1998):

1. Kategori nyaman, jika memiliki nilai $21 \leq \mathrm{THI} \leq 24$

2. Kategori cukup nyaman, jika memiliki nilai $24<\mathrm{THI} \leq 26$

3. Kategori tidak nyaman, jika memiliki nilai THI > 26

\section{HASIL DAN PEMBAHASAN \\ Karakteristik pohon di lingkungan fakultas Universitas Lancang Kuning}

Berdasar pada hasil penelitian yang telah dilakukan di lingkungan fakultas Universitas Lancang Kuning yaitu : Fakultas Kehutanan, Fakultas Ilmu Komputer, Fakultas Keguruan dan Ilmu Pendidikan, Fakultas Teknik, Fakultas

\begin{tabular}{|c|c|c|c|c|c|}
\hline $\begin{array}{l}\text { No. } \\
(\text { No. })\end{array}$ & $\begin{array}{l}\text { Nama Daerah } \\
\text { (Local name) }\end{array}$ & $\begin{array}{l}\text { Nama Ilmiah } \\
\text { (Scientific name) }\end{array}$ & $\begin{array}{c}\text { Jumlah Individu } \\
\text { (batang) } \\
\text { (Number of } \\
\text { Individuals (rods)) }\end{array}$ & $\begin{array}{c}\text { Rata2 } \\
\text { Diameter }(\mathrm{cm}) \\
(\text { Average } \\
\text { diameter }(\mathrm{cm})) \\
\end{array}$ & $\begin{array}{c}\text { Rata2 Tinggi } \\
(\mathbf{m}) \\
\text { Average } \\
\text { height }(\mathrm{m}))\end{array}$ \\
\hline 1 & Akasia Mangium & Acacia mangium & 16 & 32 & 13 \\
\hline 2 & Angsana & Pterecarpus indicus & 2 & 55 & 17 \\
\hline 3 & Bintaro & Cerbera manghas & 2 & 11 & 6 \\
\hline 4 & Cempedak & Artocarpus integra & 2 & 18 & 5 \\
\hline 5 & Eukaliptus & Eucalyptus pelita & 131 & 26 & 18 \\
\hline 6 & Gaharu & Aquilaria malaccensis & 10 & 18 & 10 \\
\hline 7 & Glodogan Tiang & Polyalthia longifolia & 10 & 18 & 9 \\
\hline 8 & Jambu Air & Syzygium sp. & 15 & 15 & 9 \\
\hline 9 & Jati & Tectona grandis & 10 & 24 & 13 \\
\hline 10 & Karet & Hevea brasiliensis & 2 & 33 & 9 \\
\hline
\end{tabular}
Pertanian, Fakultas Ilmu Budaya, Fakultas Ilmu Adminsitrasi, Fakultas Ekonomi dan Fakultas Hukum didapatkan data seperti pada Tabel 1.

Tabel 1. Karaketeristik jenis pohon di lingkungan kampus Universitas Lancang Kuning Pekanbaru (Table 1. Characteristics of tree species in the Universitas Lancang Kuning Pekanbaru campus environment) 


\begin{tabular}{|c|c|c|c|c|c|}
\hline $\begin{array}{l}\text { No. } \\
\text { (No.) }\end{array}$ & $\begin{array}{l}\text { Nama Daerah } \\
\text { (Local name) }\end{array}$ & $\begin{array}{l}\text { Nama Ilmiah } \\
\text { (Scientific name) }\end{array}$ & $\begin{array}{c}\text { Jumlah Individu } \\
\text { (batang) } \\
\text { (Number of } \\
\text { Individuals (rods)) }\end{array}$ & $\begin{array}{c}\text { Rata2 } \\
\text { Diameter }(\mathrm{cm}) \\
(\text { Average } \\
\text { diameter }(\mathrm{cm}))\end{array}$ & $\begin{array}{c}\text { Rata2 Tinggi } \\
(\mathbf{m}) \\
\text { Average } \\
\text { height }(\mathrm{m})) \\
\end{array}$ \\
\hline 11 & Kayu Putih & Melaleuca leucadendron & 1 & 53 & 25 \\
\hline 12 & Ketapang & Terminalia cattapa & 88 & 20 & 9 \\
\hline 13 & Kuras & $\begin{array}{l}\text { Dryobalanops } \\
\text { oblongifolia }\end{array}$ & 2 & 14 & 8 \\
\hline 14 & Laban & Vitex pubescens & 3 & 15 & 11 \\
\hline 15 & Mahoni & Swietenia macrophylla & 25 & 24 & 13 \\
\hline 16 & Mangga & Mangifera indica & 12 & 18 & 7 \\
\hline 17 & Manggis & Garcinia mangostana & 1 & 11 & 5 \\
\hline 18 & Matoa & Pometia pinnata & 34 & 16 & 9 \\
\hline 19 & Melinjo & Gnetum gnemon & 1 & 25 & 7 \\
\hline 20 & $\begin{array}{l}\text { Meranti } \\
\text { Balangeran }\end{array}$ & Shorea balangeran & 21 & 14 & 12 \\
\hline 21 & Nangka & Artocarpus heterophyllus & 6 & 22 & 6 \\
\hline 22 & Nyamplung & Calophyllum sp. & 2 & 34 & 11 \\
\hline 23 & Petai Cina & Leucaena leucocephala & 1 & 13 & 8 \\
\hline 24 & Pulai & Alstonia scholaris & 47 & 24 & 9 \\
\hline 25 & Roda roda & Hura crepitans & 1 & 32 & 7 \\
\hline 26 & Sendok-sendok & Endospermum sp. & 2 & 18 & 12 \\
\hline 27 & Sungkai & Peronema canescens & 14 & 22 & 12 \\
\hline 28 & Tanjung & Mimusops elengi & 1 & 24 & 7 \\
\hline 29 & Tembesu & Fagraea fragans & 8 & 23 & 9 \\
\hline 30 & Tempunik & Artocarpus rigidus & 1 & 20 & 8 \\
\hline 31 & Trembesi & Samanea saman & 1 & 17 & 4 \\
\hline \multicolumn{3}{|c|}{ Total (Total) } & 472 & & \\
\hline \multicolumn{4}{|c|}{ Rata-rata (Average) } & 23 & 10 \\
\hline
\end{tabular}

Sumber : Data Primer (2020) (Source : Primary data (2020))

Berdasar pada Tabel 1 di atas secara umum pohon-pohon yang ada di lingkungan kampus Universitas Lancang Kuning merupakan jenis-jenis yang sering dibudidayakan/ditanam oleh masyarakat sebagai tanaman pelindung di halaman rumah. Terdapat beberapa jenis pohon penghasil kayu di beberapa fakultas. Ditemukan 31 jenis pohon (tiang dan pohon) dengan jumlah individu 472 batang dan rata-rata diameter $23 \mathrm{~cm}$ serta rata-rata tingginya 10 meter. Hal ini menunjukan bahwa hampir di setiap lingkungan fakultas terdapat beberapa jenis pohon yang ditanam, meskipun jumlah individunya tidak merata. Terdapat beberapa fakultas yang jenis dan jumlah pohonnya masih relatif sedikit, perlu ada upaya dari fakultas tersebut untuk menanam beberapa jenis pohon dalam rangka membentuk lingkungan yang hijau, asri dan berdampak pada iklim mikro. Hal ini penting dalam menunjang kenyamanan proses belajar mengajar. 


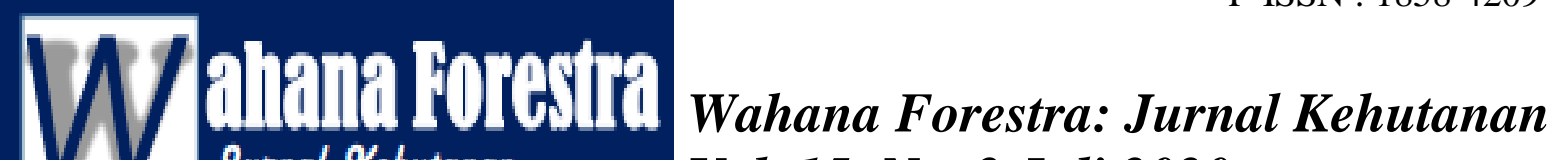 gutnal Kehutanan}

\section{Karakteristik pohon di Fakultas \\ Kehutanan}

Hasil pengukuran yang dilakukan

di lingkungan Fakulas Kehutanan
Universitas Lancang Kuning didapatkan jenis-jenis pohon dengan berbagai variasi tinggi dan diameternya seperti tercantum pada Tabel 2.

Tabel 2. Karakteristik jenis pohon di Fakultas Kehutanan

(Table 2. Characteristics of tree species at the Faculty of Forestry)

\begin{tabular}{lllccc}
\hline No. & Nama Daerah & Nama Ilmiah & $\begin{array}{c}\text { Jumlah Individu } \\
\text { (batang) }\end{array}$ & $\begin{array}{c}\text { Rata2 } \\
\text { Diameter (cm) }\end{array}$ & $\begin{array}{c}\text { Rata2 } \\
\text { Tinggi (m) }\end{array}$ \\
\hline 1 & Akasia Mangium & Acacia mangium & 2 & 22 & 7 \\
\hline 2 & Bintaro & Cerbera manghas & 2 & 11 & 6 \\
\hline 3 & Eukaliptus & Eucalyptus pelita & 41 & 24 & 18 \\
\hline 4 & Gaharu & Aquilaria malaccensis & 10 & 18 & 10 \\
\hline 5 & Jambu Air & Syzygium sp. & 7 & 16 & 8 \\
\hline 6 & Jati & Tectona grandis & 5 & 17 & 10 \\
\hline 7 & Ketapang & Terminalia cattapa & 22 & 20 & 8 \\
\hline 8 & Kuras & Dryobalanops oblongifolia & 2 & 21 & 8 \\
\hline 9 & Mahoni & Swietenia macrophylla & 5 & 20 & 13 \\
\hline 10 & Mangga & Mangifera indica & 3 & 10 & 8 \\
\hline 11 & Matoa & Pometia pinnata & 1 & 14 & 6 \\
\hline 12 & Meranti Balangeran & Shorea balangeran & 21 & 34 & 12 \\
\hline 13 & Nyamplung & Calophyllum sp. & 2 & 24 & 11 \\
\hline 14 & Pulai & Alstonia scholaris & 24 & $\mathbf{1 9}$ & 9 \\
\hline 15 & Tembesu & Fagraea fragans & 25 & 9 \\
\hline & & Total & Rata-rata & 10 & 19 \\
\hline
\end{tabular}

Sumber : Data Primer (2020)

Dari Tabel 2 di atas ditemukan 15 jenis pohon baik pohon yang biasa dibudidayakan masyarakat sebagai penghasil buah maupun jenis pohon penghasil kayu atau bahan baku pertukangan. Terdapat 149 batang pohon dengan diameter rata-rata $19 \mathrm{~cm}$ dan tinggi rata-rata 10 meter sudah cukup asri meskipun belum cukup untuk mencapai THI yang diinginkan. Selain jenis pohon tersebut, di Fakultas Kehutanan juga terdapat beberapa jenis yang masih dalam permudaan tingkat pancang (tinggi $>1,5$ meter dan diameter $<10$ centimeter). Hal ini akan memberikan dampak iklim mikro yang baik di masa mendatang.

\section{Karakteristik pohon di Fakultas Hukum}

Hasil pengukuran yang dilakukan di lingkungan Fakulas Hukum Universitas Lancang Kuning didapatkan jenis-jenis pohon dengan berbagai variasi tinggi dan diameternya seperti tercantum pada Tabel 3. 


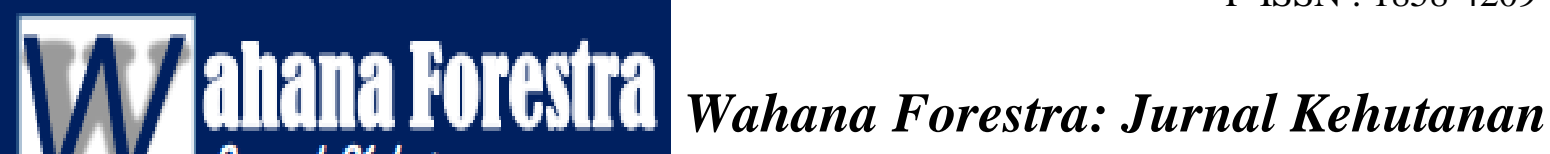 Gutenal Kehutanan \\ Vol. 15 No. 2 Juli 2020}

Tabel 3. Karakteristik jenis pohon di Fakultas Hukum

(Table 3. Characteristics of tree species in the Faculty of Law)

\begin{tabular}{cllccc}
\hline No. & Nama Daerah & Nama Ilmiah & $\begin{array}{c}\text { Jumlah Individu } \\
\text { (batang) }\end{array}$ & $\begin{array}{c}\text { Rata2 Diameter } \\
(\mathbf{c m})\end{array}$ & $\begin{array}{c}\text { Rata2 } \\
\text { Tinggi (m) }\end{array}$ \\
\hline 1 & Eukaliptus & Eucalyptus pelita & 28 & 27 & 18 \\
\hline 2 & Jambu Air & Syzygium sp. & 2 & 13 & 9 \\
\hline 3 & Jati & Tectona grandis & 1 & 15 & 10 \\
\hline 4 & Ketapang & Terminalia cattapa & 11 & 28 & 10 \\
\hline 5 & Mahoni & Swietenia macrophylla & 11 & 23 & 12 \\
\hline 6 & Matoa & Pometia pinnata & 10 & 19 & 9 \\
\hline 7 & Nangka & Artocarpus heterophyllus & 1 & 24 & 8 \\
\hline 8 & Petai Cina & Leucaena leucocephala & 1 & 13 & 8 \\
\hline 9 & Pulai & Alstonia scholaris & 3 & 23 & $\mathbf{1 1}$ \\
\hline \multicolumn{7}{c}{ Total } & $\mathbf{6 8}$ & & \\
\hline
\end{tabular}

Sumber : Data Primer (2020)

Dari Tabel 3 di atas terdapat 68 batang pohon dengan diameter rata-rata 21 $\mathrm{cm}$ dan tinggi rata-rata 11 meter masih belum cukup asri sehingga belum cukup memberikan dampak iklim mikro yang diinginkan. Dengan kondisi lingkungan yang cukup luas, perlu ada upaya untuk menanam berbagai jenis pohon dengan jumlah yang cukup.

\section{Karakteristik pohon di Fakultas Teknik}

Hasil pengukuran yang dilakukan di lingkungan Fakulas Teknik Universitas Lancang Kuning didapatkan jenis-jenis pohon dengan berbagai variasi tinggi dan diameternya seperti tercantum pada Tabel 4.

Tabel 4. Karakteristik jenis pohon di Fakultas Teknik

(Table 4. Characteristics of tree species in the Faculty of Engineering)

\begin{tabular}{cllccc}
\hline No. & Nama Daerah & Nama Ilmiah & $\begin{array}{c}\text { Jumlah Individu } \\
\text { (batang) }\end{array}$ & $\begin{array}{c}\text { Rata2 } \\
\text { Diameter }(\mathbf{c m})\end{array}$ & $\begin{array}{c}\text { Rata2 Tinggi } \\
(\mathbf{m})\end{array}$ \\
\hline 1 & Akasia mangium & Acacia mangium & 7 & 57 & 20 \\
\hline 2 & Angsana & Pterecarpus indicus & 1 & 18 & 12 \\
\hline 3 & Eukaliptus & Eucalyptus pelita & 5 & 28 & 18 \\
\hline 4 & Jambu Air & Syzygium sp. & 4 & 19 & 10 \\
\hline 5 & Ketapang & Terminalia cattapa & 22 & 19 & 12 \\
\hline 6 & Matoa & Pometia pinnata & 1 & 14 & 7 \\
\hline 7 & Melinjo & Gnetum gnemon & 1 & 25 & 5 \\
\hline 8 & Nangka & Artocarpus heterophyllus & 1 & 27 & 7 \\
\hline 9 & Roda roda & Hura crepitans & 1 & 32 & 13 \\
\hline 10 & Sungkai & Peronema canescens & 5 & $\mathbf{4 8}$ & $\mathbf{1 1}$ \\
\hline \multicolumn{7}{r}{} & Total & & $\mathbf{2 6}$ \\
\hline
\end{tabular}




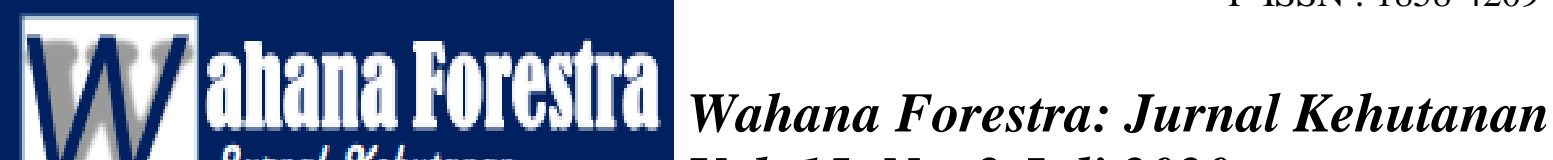 Gutenal Kehutanan}

Sumber : Data Primer (2020)

Dari Tabel 4 di atas terdapat 48 batang pohon dengan diameter rata-rata 26 centimeter dan tinggi rata-rata 11 meter masih belum cukup asri sehingga belum cukup memberikan dampak iklim mikro yang diinginkan. Dengan kondisi lingkungan yang cukup luas, perlu ada upaya untuk menanam berbagai jenis pohon dengan jumlah yang cukup.

\section{Karakteristik pohon di Fakultas Ilmu Budaya}

Hasil pengukuran yang dilakukan di lingkungan Fakulas Ilmu Budaya Universitas Lancang Kuning didapatkan jenis-jenis pohon dengan berbagai variasi tinggi dan diameternya seperti tercantum pada Tabel 5

Tabel 5. Karakteristik jenis pohon di Fakultas Ilmu Budaya

\begin{tabular}{cllccc}
\hline No. & Nama Daerah & Nama Ilmiah & $\begin{array}{c}\text { Jumlah Individu } \\
\text { (batang) }\end{array}$ & $\begin{array}{c}\text { Rata2 } \\
\text { Diameter (cm) }\end{array}$ & $\begin{array}{c}\text { Rata2 } \\
\text { Tinggi (m) }\end{array}$ \\
\hline 1 & Angsana & Pterecarpus indicus & 1 & 91 & 22 \\
\hline 2 & Jati & Tectona grandis & 4 & 40 & 18 \\
\hline 3 & Ketapang & Terminalia cattapa & 2 & 27 & 14 \\
\hline 4 & Matoa & Pometia pinnata & 2 & 19 & 8 \\
\hline 5 & Pulai & Alstonia scholaris & 2 & 27 & 9 \\
\hline 6 & Tanjung & Mimusops elengi & 1 & 24 & 7 \\
\hline 7 & Tembesu & Fagraea fragans & 6 & 21 & 10 \\
\hline \multicolumn{7}{r}{} & Total $\quad \mathbf{1 8}$ & $\mathbf{3 5}$ & $\mathbf{1 3}$ \\
\hline
\end{tabular}

Sumber : Data Primer (2020)

Dari Tabel 5 di atas terdapat 18 batang pohon dengan diameter rata-rata 35 centimeter dan tinggi rata-rata 13 meter masih belum cukup asri sehingga belum cukup memberikan dampak iklim mikro yang diinginkan. Dengan kondisi lingkungan yang cukup luas dan dikelilingi oleh jalan aspal, akan menimbulkan iklim mikro yang kurang baik. Meskipun pohon sudah cukup besar namun perlu ada upaya untuk menanam berbagai jenis pohon dengan jumlah yang cukup.

\section{Karakteristik pohon di Fakultas Ilmu Administrasi}

Hasil pengukuran yang dilakukan di lingkungan Fakulas Ilmu Administrasi Universitas Lancang Kuning didapatkan jenis-jenis pohon dengan berbagai variasi tinggi dan diameternya seperti tercantum pada Tabel 6.

Tabel 6. Karakteristik jenis pohon di Fakultas Ilmu Administrasi

\begin{tabular}{cllccc}
\hline No. & Nama Daerah & Nama Ilmiah & $\begin{array}{c}\text { Jumlah Individu } \\
\text { (batang) }\end{array}$ & $\begin{array}{c}\text { Rata2 Diameter } \\
(\mathbf{c m})\end{array}$ & $\begin{array}{c}\text { Rata2 } \\
\text { Tinggi (m) }\end{array}$ \\
\hline 1 & Akasia & Acacia mangium & 4 & 22 & 14 \\
\hline 2 & Glodogan Tiang & Polyalthia longifolia & 2 & 19 & 9 \\
\hline 3 & Karet & Hevea brasiliensis & 2 & 33 & 9 \\
\hline 4 & Ketapang & Terminalia cattapa & 2 & 16 & 8 \\
\hline
\end{tabular}




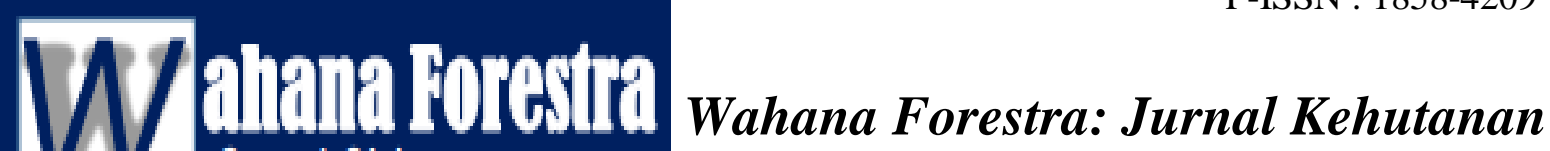 gutnal Kehutanan \\ Vol. 15 No. 2 Juli 2020}

\begin{tabular}{cllccc}
\hline No. & Nama Daerah & Nama Ilmiah & $\begin{array}{c}\text { Jumlah Individu } \\
\text { (batang) }\end{array}$ & $\begin{array}{c}\text { Rata2 Diameter } \\
\text { (cm) }\end{array}$ & $\begin{array}{c}\text { Rata2 } \\
\text { Tinggi (m) }\end{array}$ \\
\hline 5 & Mahoni & Swietenia macrophylla & 1 & 18 & 15 \\
\hline 6 & Matoa & Pometia pinnata & 6 & 26 & 10 \\
\hline 7 & Nangka & Artocarpus heterophyllus & 1 & 29 & 5 \\
\hline 8 & Sungkai & Peronema canescens & 5 & 29 & 12 \\
\hline \multicolumn{7}{c}{ Total } & $\mathbf{2 3}$ & $\mathbf{2 4}$ & $\mathbf{1 0}$ \\
\hline \multicolumn{7}{c}{ Rata-rata }
\end{tabular}

Sumber : Data Primer (2020)

Dari Tabel 6 di atas terdapat 23 batang pohon dengan diameter rata-rata 24 centimeter dan tinggi rata-rata 10 meter masih belum cukup asri sehingga belum cukup memberikan dampak iklim mikro yang diinginkan. Dengan kondisi lingkungan yang cukup luas, perlu ada upaya untuk menanam berbagai jenis pohon dengan jumlah yang cukup.

\section{Karakteristik pohon di Fakultas Ekonomi}

Hasil pengukuran yang dilakukan di lingkungan Fakulas Ekonomi Universitas Lancang Kuning didapatkan jenis-jenis pohon dengan berbagai variasi tinggi dan diameternya seperti tercantum pada Tabel 7.

Tabel 7. Karakteristik jenis pohon di Fakultas Ekonomi

\begin{tabular}{lllccc}
\hline No. & Nama Daerah & Nama Ilmiah & $\begin{array}{c}\text { Jumlah Individu } \\
\text { (batang) }\end{array}$ & $\begin{array}{c}\text { Rata2 } \\
\text { Diameter (cm) }\end{array}$ & $\begin{array}{c}\text { Rata2 } \\
\text { Tinggi (m) }\end{array}$ \\
\hline 1 & Eukaliptus & Eucalyptus pelita & 17 & 21 & 13 \\
\hline 2 & Glodogan Tiang & Polyalthia longifolia & 6 & 20 & 5 \\
\hline 3 & Kayu Putih & Melaleuca leucadendron & 1 & 53 & 25 \\
\hline 4 & Ketapang & Terminalia cattapa & 21 & 16 & 6 \\
\hline 5 & Mahoni & Swietenia macrophylla & 1 & 23 & 8 \\
\hline 6 & Matoa & Pometia pinnata & 7 & 13 & 9 \\
\hline 7 & Nangka & Artocarpus heterophyllus & 2 & 27 & 9 \\
\hline 8 & Pulai & Alstonia scholaris & 8 & & $\mathbf{2 3}$ \\
\hline & & Total $\quad$ Rata-rata & $\mathbf{6 3}$ & $\mathbf{1 0}$ \\
\hline
\end{tabular}

Sumber : Data Primer (2020)

Dari Tabel 7 di atas terdapat 63 batang pohon dengan diameter rata-rata 23 centimeter dan tinggi rata-rata 10 meter masih belum cukup asri sehingga belum cukup memberikan dampak iklim mikro yang diinginkan. Dengan kondisi lingkungan yang cukup luas, perlu ada upaya untuk menanam berbagai jenis pohon dengan jumlah yang cukup.

\section{Karakteristik pohon di Fakultas Pertanian}

Hasil pengukuran yang dilakukan di lingkungan Fakulas Pertanian Universitas Lancang Kuning didapatkan jenis-jenis 


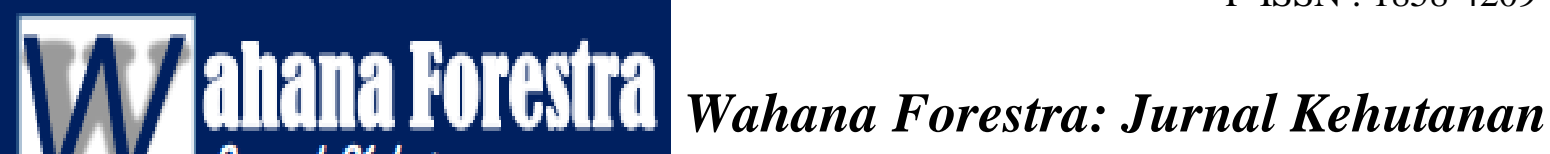 gutnal Kehutanan \\ Vol. 15 No. 2 Juli 2020}

pohon dengan berbagai variasi tinggi dan diameternya seperti tercantum pada Tabel 8.

Tabel 8. Karakteristik jenis pohon di Fakultas Pertanian

\begin{tabular}{cllccc}
\hline No. & Nama Daerah & Nama Ilmiah & $\begin{array}{c}\text { Jumlah Individu } \\
\text { (batang) }\end{array}$ & $\begin{array}{c}\text { Rata2 } \\
\text { Diameter (cm) }\end{array}$ & $\begin{array}{c}\text { Rata2 Tinggi } \\
(\mathbf{m})\end{array}$ \\
\hline 1 & Akasia & Acacia mangium & 1 & 25 & 10 \\
\hline 2 & Cempedak & Artocarpus integra & 2 & 18 & 5 \\
\hline 3 & Glodogan Tiang & Polyalthia longifolia & 2 & 15 & 14 \\
\hline 4 & Jambu Air & Syzygium sp. & 2 & 14 & 9 \\
\hline 5 & Ketapang & Terminalia cattapa & 5 & 19 & 10 \\
\hline 6 & Mahoni & Swietenia macrophylla & 7 & 34 & 16 \\
\hline 7 & Mangga & Mangifera indica & 9 & 17 & 6 \\
\hline 8 & Manggis & Garcinia mangostana & 1 & 11 & 5 \\
\hline 9 & Matoa & Pometia pinnata & 6 & 16 & 6 \\
\hline 10 & Nangka & Artocarpus heterophyllus & 1 & 18 & 7 \\
\hline 11 & Pulai & Alstonia scholaris & 10 & 20 & 10 \\
\hline 12 & Sungkai & Peronema canescens & 4 & $\mathbf{1 9}$ & $\mathbf{9}$ \\
\hline & & Total & $\mathbf{5 0}$ & & 5 \\
\hline
\end{tabular}

Sumber : Data Primer (2020)

Dari Tabel 8 di atas terdapat 50 batang pohon dengan diameter rata-rata 19 centimeter dan tinggi rata-rata 9 meter masih belum cukup asri sehingga belum cukup memberikan dampak iklim mikro yang diinginkan. Dengan kondisi lingkungan yang cukup luas dan banyak lahan terbuka, akan menimbulkan iklim mikro yang kurang baik. Perlu ada upaya untuk menanam berbagai jenis pohon dengan jumlah yang cukup.

Karakteristik pohon di Fakultas IImu Komputer

Hasil pengukuran yang dilakukan di lingkungan Fakulas Ilmu Komputer Universitas Lancang Kuning didapatkan jenis-jenis pohon dengan berbagai variasi tinggi dan diameternya seperti tercantum pada Tabel 9.

Tabel 9. Karakteristik jenis pohon di Fakultas Ilmu Komputer

\begin{tabular}{cllccc}
\hline No. & Nama Daerah & Nama Ilmiah & $\begin{array}{c}\text { Jumlah Individu } \\
\text { (batang) }\end{array}$ & $\begin{array}{c}\text { Rata2 } \\
\text { Diameter (cm) }\end{array}$ & Rata2 Tinggi (m) \\
\hline 1 & Eukaliptus & Eucalyptus pelita & 14 & 31 & 20 \\
\hline 2 & Sendok-sendok & Endospermum sp. & 2 & 18 & 12 \\
\hline 3 & Tempunik & Artocarpus rigidus & 1 & 20 & 4 \\
\hline 4 & Trembesi & Samanea saman & 1 & 17 & $\mathbf{1 1}$ \\
\hline \multicolumn{7}{c}{ Total } & $\mathbf{1 8}$ & $\mathbf{2 1}$ & \\
\hline
\end{tabular}

Sumber : Data Primer (2020) 
Dari Tabel 9 di atas terdapat 18 batang pohon dengan diameter rata-rata 21 centimeter dan tinggi rata-rata 11 meter masih belum cukup asri sehingga belum cukup memberikan dampak iklim mikro yang diinginkan. Dengan kondisi lingkungan yang cukup luas, perlu ada upaya untuk menanam berbagai jenis pohon dengan jumlah yang cukup

\section{Karakteristik pohon di Fakultas Keguruan dan Ilmu Pendidikan}

Hasil pengukuran yang dilakukan di lingkungan Fakulas Keguruan dan Ilmu Pendidikan Universitas Lancang Kuning didapatkan jenis-jenis pohon dengan berbagai variasi tinggi dan diameternya seperti tercantum pada Tabel 10.

Tabel 10. Karakteristik jenis pohon di Fakultas Keguruan dan Ilmu Pendidikan

\begin{tabular}{clcccc}
\hline No. & Nama Daerah & Nama Ilmiah & $\begin{array}{c}\text { Jumlah Individu } \\
\text { (batang) }\end{array}$ & $\begin{array}{c}\text { Rata2 } \\
\text { Diameter }(\mathbf{c m})\end{array}$ & $\begin{array}{c}\text { Rata2 Tinggi } \\
(\mathbf{m})\end{array}$ \\
\hline 1 & Akasia mangium & Acacia mangium & 2 & 34 & 14 \\
\hline 2 & Eukaliptus & Eucalyptus pelita & 26 & 27 & 19 \\
\hline 3 & Ketapang & Terminalia cattapa & 3 & 19 & 8 \\
\hline 4 & Laban & Vitex pubescens & 3 & 15 & 9 \\
\hline 5 & Matoa & Pometia pinnata & 1 & 13 & 11 \\
\hline \multicolumn{7}{c}{ Total $\quad$ Rata-rata } \\
\hline
\end{tabular}

Sumber : Data Primer (2020)

Dari Tabel 10 di atas terdapat 35 batang pohon dengan diameter rata-rata 22 centimeter dan tinggi rata-rata 12 meter masih belum cukup asri sehingga belum cukup memberikan dampak iklim mikro yang diinginkan. Dengan kondisi lingkungan yang cukup luas dan pohon didominasi oleh Eukaliptus, perlu ada upaya untuk menanam berbagai jenis pohon dengan jumlah yang cukup

\section{Tingkat Kenyamanan}

Berdasar pada hasil pengukuran suhu dan kelembaban di lingkungan fakultas Universitas Lancang Kuning, didapatkan suhu dan kelembaban harian. Suhu dan kelembaban harian diukur pada waktu pagi, siang dan sore. Hasil pengukuran tersebut dirata-rata menjadi suhu rata-rata harian dan kelembaban relatif rata-rata harian. Data-data tersebut selanjutnya digunakan untuk menghitung "Indeks Suhu Kelembaban" atau "Temperature Humidity Index (THI)". Temperature Humidity Index selengkapnya tercantum pada Tabel 11

Tabel 11. Temperature Humidity Index (THI) di lingkungan fakultas Universitas Lancang Kuning

\begin{tabular}{|c|c|c|c|c|c|c|c|c|c|c|c|}
\hline \multirow{2}{*}{ No } & \multirow{2}{*}{ Lokasi } & \multicolumn{3}{|c|}{ Suhu Harian $\left({ }^{\circ} \mathbf{C}\right)$} & \multirow{2}{*}{$\begin{array}{c}\mathbf{T} \\
\left({ }^{\circ} \mathbf{C}\right)\end{array}$} & \multicolumn{3}{|c|}{ Kelembaban (\%) } & \multirow{2}{*}{$\begin{array}{l}\text { RH } \\
(\%)\end{array}$} & \multirow{2}{*}{$\begin{array}{l}\text { THI } \\
\left({ }^{\circ} \mathrm{C}\right)\end{array}$} & \multirow{2}{*}{ Kategori } \\
\hline & & Pagi & Siang & Sore & & Pagi & Siang & Sore & & & \\
\hline 1 & Fakultas Kehutanan & 29.3 & 31.5 & 31.6 & 30.4 & 81.3 & 69.3 & 61.0 & 73.3 & 28.8 & Tidak Nyaman \\
\hline 2 & $\begin{array}{l}\text { Fakultas Ilmu } \\
\text { Komputer }\end{array}$ & 30.0 & 32.4 & 32.8 & 31.3 & 78.3 & 65.0 & 62.7 & 71.1 & 29.5 & Tidak Nyaman \\
\hline
\end{tabular}




\section{W-ISSN : 1858-4209
Gol. 15 No. 2 Juli 2020
Vohutanan}

\begin{tabular}{|c|c|c|c|c|c|c|c|c|c|c|c|}
\hline \multirow{2}{*}{ No } & \multirow{2}{*}{ Lokasi } & \multicolumn{3}{|c|}{ Suhu Harian $\left({ }^{\circ} \mathbf{C}\right)$} & \multirow{2}{*}{$\begin{array}{c}\mathbf{T} \\
\left({ }^{\circ} \mathbf{C}\right)\end{array}$} & \multicolumn{3}{|c|}{ Kelembaban (\%) } & \multirow{2}{*}{$\begin{array}{l}\text { RH } \\
(\%)\end{array}$} & \multirow{2}{*}{$\begin{array}{l}\text { THI } \\
\left({ }^{\circ} \mathrm{C}\right)\end{array}$} & \multirow{2}{*}{ Kategori } \\
\hline & & Pagi & Siang & Sore & & Pagi & Siang & Sore & & & \\
\hline 3 & FKIP & 30.1 & 32.9 & 32.9 & 31.5 & 77.7 & 61.3 & 63.0 & 69.9 & 29.6 & Tidak Nyaman \\
\hline 4 & Fakultas Teknik & 30.1 & 33.0 & 32.8 & 31.5 & 78.7 & 60.7 & 64.7 & 70.7 & 29.6 & Tidak Nyaman \\
\hline 5 & Fakultas Pertanian & 30.1 & 33.0 & 32.7 & 31.4 & 78.0 & 59.3 & 65.0 & 70.1 & 29.6 & Tidak Nyaman \\
\hline 6 & $\begin{array}{l}\text { Fakultas Ilmu } \\
\text { Administrasi }\end{array}$ & 29.8 & 32.9 & 31.4 & 31.0 & 79.3 & 60.0 & 70.3 & 72.3 & 29.3 & Tidak Nyaman \\
\hline 7 & Fakultas Ekonomi & 29.8 & 33.0 & 31.2 & 31.0 & 80.0 & 59.3 & 70.0 & 72.3 & 29.3 & Tidak Nyaman \\
\hline 8 & $\begin{array}{l}\text { Fakultas Ilmu } \\
\text { Budaya }\end{array}$ & 30.0 & 33.3 & 31.7 & 31.2 & 78.7 & 59.0 & 65.3 & 70.4 & 29.4 & Tidak Nyaman \\
\hline 9 & Fakultas Hukum & 30.0 & 33.2 & 33.1 & 31.6 & 78.3 & 58.0 & 72.0 & 71.7 & 29.8 & Tidak Nyaman \\
\hline
\end{tabular}

Sumber : Data primer (2020)

Keterangan : $\mathrm{T}=$ Suhu rata-rata harian; $\mathrm{RH}=$ Relative Humidity/Kelembaban Relatif rata-rata harian; THI = Temperature Humidity Index

Berdasar pada Tabel 11 diatas secara umum THI di seluruh fakultas dalam kategori "Tidak Nyaman". Sebanyak 8 fakultas $\mathrm{THI}$ di atas $29^{\circ} \mathrm{C}$, hanya 1 fakultas yang THI di bawah $29^{\circ} \mathrm{C}$ yaitu Fakultas Kehutanan. Hal tersebut terjadi karena sebagian lingkungan fakultas di Universitas Lancang Kuning masih cukup banyak yang terbuka, belum banyak pohon yang ditanam. Kurangnya pohon di lingkungan fakultas menjadi salah satu penyebab $T H I$ menjadi tinggi atau tidak nyaman

\section{KESIMPULAN DAN SARAN Kesimpulan}

Setelah dilakukan penelitian tentang peran pohon di lingkungan kampus Universitas Lancang Kuning dapat disimpulkan sebagai berikut :

1. Ditemukan sebanyak 31 jenis pohon dengan jumlah 472 batang dengan diameter rata-rata 23 centimeter dan tinggi rata-rata 10 meter

2. Seluruh fakultas di lingkungan Universitas Lancang Kuning termasuk dalam kategori "tidak nyaman".

\section{Saran}

Saran yang dapat diberikan dalam penelitian adalah sebagai berikut :

1. Agar dapat dilakukan penanaman berbagai jenis pohon dengan jumlah yang cukup pada setiap lingkungan fakultas.

2. Diperlukan sosialisasi tentang pentingnya fungsi pohon bagi lingkungan dan manusia.

\section{UCAPAN TERIMA KASIH}

Ucapan terima kasih disampaikan kepada pihak Fakultas Kehutanan Universitas Lancang Kuning Pekanbaru yang telah membiayai penelitian ini dan pihak lain yang membantu penyelesaian tulisan ini

\section{DAFTAR PUSTAKA}

Ahmad, F., Arifin, H., Dahlan, E., Effendy, S., dan Kurniawan, R. 2012. Analisis hubungan luas ruang terbuka hijau (rth) dan perubahan suhu di Kota Palu. Jurnal Hutan Tropis. 13(2):173-180.

Brooks, R. G. 1988. Site Planning :Evaluation, Process, and 
Development. Buku. Prentice Hall. New Jersey. 322 p.

Bunyamin, Z., \& Aqil, M. (2010). Analisis Iklim Mikro Tanaman Jagung (Zea mays L) pada Sistem Tanaman Sisip. In Pekan Serealia Nasional. Maros:Kementan.

Dahlan, E.N. 1992. Hutan Kota untuk Pengelolaan dan Peningkatan Kualitas Lingkungan Hidup. Buku. Asosiasi Pengusaha Hutan Indonesia (APHI). Jakarta. 92 p.

Dahlan. 2004. Membangun Kota Kebun Bernuansa Hutan Kota. Buku. IPB Press. Bogor. 216 p.

Dahlan, E. N. (2013). Kota Hijau Hutan Kota. Bogor: IPB Press.

Emmanuel, R. (2005). Thermal comfort implications of urbanization in a warm-humid city: The Colombo Metropolitan Region (CMR), Sri Lanka. Building and Environment, 40(12), 1591-1601. https://doi.org/10.1016/j.buildenv. $\underline{20} 04.12 .004$

Evert, A., Yuwono, S. B., \& Daryat. (2017). Tingkat Kenyamanan di Hutan Kota Patriot Bina Bangsa Kota Bekasi. Sylva Lestari, 5(1), $14-25$.

Gates, D. M. 1972. Man and His Enviroment : Climate. Buku. Harper and Row. New York. 175 p.

Gucci, M. P. R., Zulkarnaini, \& Anita, S. (2016). Analisis Perbedaan Iklim
Mikro Terhadap Kenyamanan Pengunjung Pada Ruang Terbuka Hijau Di Kota Pekanbaru. Jurnal Ilmu Lingkungan, 10(2), 112-120.

Hadi, R., Lila, K. A., Gunadi, I.G.A. 2012. Evaluasi indeks kenyamanan taman kota (Lapangan Puputan Badung I Gusti Ngurah Made Agung Denpasar, Bali). Jurnal Agroekoteknologi Tropika. 2(1): 44-45.

Handoko. 1994. Klimatologi Dasar. Buku. Pustaka Jaya. Bogor. 192 p.

Irwan, S.N.R., Kharuddin. 2010. Studi kenyamanan untuk aktivitas di lanskap Hutan Kota UGM. Jurnal Ilmu Kehutanan. 4(2) : 105-112.

Kartasapoetra, A. G. 2006. Klimatologi : Pengaruh Iklim Tehadap Tanah dan Tanaman. Buku. Bumi Aksara. Jakarta. 113 p.

Lakitan, B. 1994. Dasar-dasar Klimatologi. Buku. Raja Grafindo Persada. Jakarta 173 p.

Laurie, M. 1986. Pengantar Kepada Arsitektur Pertamanan. Buku. Multi Mata Media. Bandung. 133 p.

Lay dan Bey, A. 1990. Metode Kausal dan Time Series Dalam Analisis Data Iklim. Buku. Institut Pertanian Bogor. 75 p.

Nieuwolt,S., Mc Gregor G. R. 1998. Tropical Climatology. Buku. England (UK) : John Wiley \& Sons Ltd.352 p. 
Prasetyo, I. 1997. Studi iklim mikro jalur hijau di Kotamadya Bandung. Skripsi. Intutut Pertanian Bogor. Bogor. 69 p.

Prawirowardoyo, S. 1996. Meteorologi. Buku. ITB. Bandung. 226 p.

Rahmah, D. F., \& Sobirin. (2017). Intensitas Penyejukan Taman di Wilayah Sekitar Kebun Raya Bogor (Vol. 2). Bandung.

Rahmawati, S.N. 2014. Kemampuan Hutan Kota Dalam Ameliorasi Iklim Mikro di Kampus IPB Darmaga. Skripsi. Institut Pertanian Bogor. Bogor. 32 p.

Santoso, M. E. 1986. Alat Pengukur Cuaca. Buku. Institut Pertanian Bogor. Bogor. 95 p.

Simonds, J. O. 1983. Landscape Architecture. Buku. Mc Graw-Hill. New York :.396 p.

Sosrodarsono dan Takeda. 1999. Hutan Kota : Peranan dan Permasalahannya. Buku. Institut Pertanian Bogor. Bogor. 125 p.

Xin, C., Onishi, A., \& Imura, H. (2010). Quantifying the Cool Island Intensity of Urban Parks Using ASTER and IKONOS Data. Landscape and Urban Planning. 